\title{
Association of the $\mathrm{CHADS}_{2}$ and $\mathrm{CHA}_{2} \mathrm{DS}_{2}$-VASc scores with left atrial enlargement: a prospective cohort study of unselected atrial fibrillation patients
}

\author{
Anna Hrynkiewicz-Szymanska • Miroslaw Dluzniewski • \\ Anna E. Platek · Filip M. Szymanski · Joanna Syska-Suminska • \\ Agnieszka Klos-Szadryn • Marta Glinka • Malgorzata Strojek • \\ Alicja Kuciej • Monika Tomaszewska-Kiecana
}

Published online: 10 December 2014

(C) The Author(s) 2014. This article is published with open access at Springerlink.com

\begin{abstract}
Assessment of thromboembolic risk is crucial for proper management of atrial fibrillation (AF) patients. Currently used risk score base only on scarce clinical data and do not take into consideration parameters including echocardiographic findings. The aim of this study was to evaluate if left atrium (LA) enlargement is associated with higher thromboembolic risk assessed by $\mathrm{CHADS}_{2}$ and $\mathrm{CHA}_{2} \mathrm{DS}_{2}$-VASc scores in a cohort of unselected nonvalvular $\mathrm{AF}$ patients. Data from $582 \mathrm{AF}$ hospitalizations occurring between November 2012 and January 2014 were analyzed. All patients underwent a standard transthoracic echocardiography and had their thromboembolic risk assessed in both $\mathrm{CHADS}_{2}$ and $\mathrm{CHA}_{2} \mathrm{DS}_{2}$-VASc scores. In 494 enrolled patients $(48.5 \%$ male; mean age $73.4 \pm 11.5$ years) AF was classified as paroxysmal in 233 $(47.3 \%)$, as persistent in $109(22.1 \%)$, and as permanent in $151(30.6 \%)$ patients. LA was enlarged in $426(86.2 \%)$ patients. Enlargement was classified as mild in 99 (20.0\%) patients, as moderate in $130(26.3 \%)$ patients, and as severe in 196 (39.7\%) patients. Patients with enlarged LA had higher mean $\mathrm{CHADS}_{2}$ score $(2.0 \pm 1.5$ vs. $2.6 \pm 1.3$; $p=0.0005) \quad$ and $\quad \mathrm{CHA}_{2} \mathrm{DS}_{2}$-VASc $\quad(3.8 \pm 2.0 \quad$ vs. $4.4 \pm 1.8 ; p=0.02)$ score than patients with normal LA. The both mean scores rose along with rising LA diameter.
\end{abstract}

A. Hrynkiewicz-Szymanska ( $₫) \cdot$ M. Dluzniewski . J. Syska-Suminska · A. Klos-Szadryn · M. Glinka · M. Strojek · A. Kuciej · M. Tomaszewska-Kiecana Department of Cardiology, Hypertension and Internal Diseases, Medical University of Warsaw, Kondratowicza 8 Street, 03-242 Warsaw, Poland

e-mail: anna.szymanska@wum.edu.pl

A. E. Platek · F. M. Szymanski

1st Department of Cardiology, Medical University of Warsaw,

1A Banacha Street, 02-097 Warsaw, Poland
LA enlargement is highly prevalent in AF patients. Higher thromboembolic risk assessed by both $\mathrm{CHADS}_{2}$ and $\mathrm{CHA}_{2} \mathrm{DS}_{2}$-VASc scores is associated with presence of LA enlargement. Echocardiographically assessed LA size may be an additional parameter useful in thromboembolic risk stratification of AF patients.

Keywords Atrial fibrillation - Left atrial enlargement . Stroke risk $\cdot \mathrm{CHADS}_{2} \cdot \mathrm{CHA}_{2} \mathrm{DS}_{2}$-VASc

\section{Introduction}

Assessment of thromboembolic risk is crucial for proper management of atrial fibrillation (AF) patients and prevention of one of its most important complications-an cardioembolic stroke. AF is directly responsible for occurrence of approximately 1 out of every 5 strokes [1]. Therefore current guidelines recommend anticoagulation therapy in patients with elevated stroke risk [2, 3]. Tools recommended for the stroke risk assessment are the $\mathrm{CHADS}_{2}$ and $\mathrm{CHA}_{2} \mathrm{DS}_{2}$-VASc scores. Those are point scores, which calculate the annual stroke risk basing on clinical parameters like presence of comorbidities including age, congestive heart failure, diabetes mellitus or history of stroke $[4,5]$. Unfortunately, as previously reported for the case of obstructive sleep apnea, the $\mathrm{CHADS}_{2}$ and $\mathrm{CHA}_{2} \mathrm{DS}_{2}$-VASc, like many point scores, are likely to omit many important parameters associated with elevated thromboembolic risk [6].

One of the stroke risk factors overlooked by the scores is the size of left atrium (LA). AF-associated thrombi, which are responsible for stroke, are forming mostly in the LA and its appendage. LA size and its morphology were previously shown to be predictive of thromboembolic risk 
$[7,8]$. Therefore, on one side presence of the enlarged atrium is associated with greater thromboembolic risk, and worsens the outcome of invasive strategies for sinus rhythm restoration [9]. On the other hand, in many cases LA enlargement is partially caused by the AF-related hemodynamic disturbances or comorbidities highly prevalent in $\mathrm{AF}$ patients, and it was shown that LA size tends to decrease when sinus rhythm is restored [10]. The mutual exacerbation of AF and LA enlargement often coexist in patients, but LA size was not implemented into the currently used risk assessment schemes.

The aim of this study was to evaluate if LA enlargement is associated with higher thromboembolic risk assessed by $\mathrm{CHADS}_{2}$ and $\mathrm{CHA}_{2} \mathrm{DS}_{2}$-VASc scores in a cohort of unselected non-valvular AF patients.

\section{Methods}

\section{Study population}

The study was designed and conducted with the accordance of the Declaration of Helsinki and it was approved by the Regional Ethics Committee. We prospectively analyzed data on continuous hospitalizations for AF that occurred between November 2012 and January 2014 in a tertiary University Hospital Cardiology Department. Inclusion criteria were age $\geq 18$ years, primary diagnosis of $\mathrm{AF}$, echocardiographic evaluation underwent during current hospitalization. We excluded patients with valvular AF, fatal condition with estimated life expectancy of $\leq 6$ months, or those who did not give an informed consent for the participation in the study. In the set of 582 hospitalizations included in the analysis, 494 unique patients were identified. Medical history was taken in all patients on admission by a qualified physician. Data included information on thromboembolic and cardiovascular risk factors.

\section{Diagnosis of atrial fibrillation}

AF diagnosis was made with respect of the European Society of Cardiology Guidelines for the management of AF from 2010 and its update in 2012 [2, 3]. It was verified in all cases by two independent expert cardiologists, and required at least one episode of the $\mathrm{AF}$ recorded in a 12-lead electrocardiogram (ECG) made during the current hospitalization or an episode documented AF in a 12-lead ECG and/or 24-h ECG Holter monitoring in 6 months prior to the study enrollment. AF was defined as at least $30 \mathrm{~s}$ of an irregular heart rhythm without detectable $\mathrm{P}$ waves. Assessment of AF type was made basing on medical records. Paroxysmal AF was defined as a self-terminating episode, (usually within $48 \mathrm{~h}$, which may continue for up to 7 days), whereas persistent $\mathrm{AF}$ was diagnosed when arrhythmia episode either lasted longer than 7 days or required termination by cardioversion, either with drugs or by direct current cardioversion. Permanent AF was diagnosed in the study population only if it was decided not to pursue rhythm control strategy.

Assessment of thromboembolic and cardiovascular risk

Data on classical cardiovascular risk factors were collected and all patients had their stroke risk assessed in the $\mathrm{CHADS}_{2}$ and $\mathrm{CHA}_{2} \mathrm{DS}_{2}$-VASc scores according to the current scoring guidelines $[4,5]$. In the $\mathrm{CHADS}_{2}$ score, one point was assigned for history of congestive heart failure, diabetes, hypertension, and age $\geq 75$ years, whereas in the $\mathrm{CHA}_{2} \mathrm{DS}_{2}$-VASc score it was assigned for age between 65 and 74 years, female sex, history of hypertension, diabetes, heart failure, and vascular disease (history of myocardial infarction, presence of complex aortic plaque, or peripheral artery disease). Conditions linked with 2 point scores were history of stroke or transient ischemic attach (TIA) for CHADS $_{2}$ score and history of stroke or TIA, and age $\geq 75$ years in $\mathrm{CHA}_{2} \mathrm{DS}_{2}$-VASc score. Diagnosis of all factors implemented into the models was made basing on eligible medical records, taking prescription drugs applicable for the respective disease (i.e. hypoglycemic agents for diabetes), or as a de novo diagnosis according to the current diagnostic criteria.

\section{Echocardiographic evaluation}

As soon as their clinical state was stable, all patients underwent a standard, full transthoracic echocardiography (TTE) according to the current standards of the European Association of Cardiovascular Imaging [11, 12]. All TTEs were performed using GE Vivid 7 Ultrasound Systems. Examinations were made and analyzed by two experienced echocardiographers. Standard views optimal for echocardiographic assessment were obtained. To avoid bias measurements were taken three times then averaged. The following parameters were measured for the purpose of the study: left ventricular end-diastolic diameter (LVEDd), left ventricular ejection fraction (LVEF), interventricular septal end-systolic diameter (IVSd), left ventricular posterior wall diameter (LVPWd) at end-diastole, left atrial diameter (LAd), and right ventricular diameter (RVEDd). Enddiastole and end-systole were defined as the frame in the cardiac cycle in which the cardiac dimension was the largest and the smallest, respectively. LVEDd, IVSd, and LVPWd were measured from the parasternal long axis view using $2 \mathrm{D}$ echocardiography at the level of the mitral valve leaflet tips. LAd was measured using $2 \mathrm{D}$ obtained from the parasternal long axis view from the trailing edge 
of the posterior aortic wall to the leading edge of the posterior LA wall at the ventricular end-systole when the LA chamber is at its greatest dimension. Right ventricle was measured at the proximal portion of the RV outflow tract from the parasternal window at end-diastole using the long axis view. LVEF was calculated using the biplane method of discs (modified Simpson's rule). Enlargement of the LA was classified into the four categories: normal, mildly enlarged, moderately enlarged, and severely enlarged in accordance with the European Society of Cardiology guidelines [11]. LA size was considered normal when LAd was $<39 \mathrm{~mm}$ in women and $<41 \mathrm{~mm}$ in men, otherwise it was considered enlarged. Mild enlargement was defined as LAd values $39-42 \mathrm{~mm}$ in women and $41-46 \mathrm{~mm}$ in men, moderate enlargement for $43-46 \mathrm{~mm}$ in women and $47-51 \mathrm{~mm}$ in men, and severe enlargement for $\geq 47 \mathrm{~mm}$ in women and $\geq 52 \mathrm{~mm}$ in men. Additionally, patients were divided according the LAd index, calculated as LAd/body surface area (calculated from Du Bois formula $0.007184 \times$ weight $^{0.425} \times$ height $^{0.725}$ ). LAd indexassessed atrial enlargement was classified as follows: normal LA- $15-23 \mathrm{~mm} / \mathrm{m}^{2}$, mildly enlarged LA$24-26 \mathrm{~mm} / \mathrm{m}^{2}$, moderately enlarged-27-29 $\mathrm{mm} / \mathrm{m}^{2}$, and severely enlarged as $\geq 30 \mathrm{~mm} / \mathrm{m}^{2}$, both in men and women.

\section{Statistical analysis}

Data were tested for normality using the KolmogorovSmirnov test. Continuous data are presented as mean and $95 \%$ confidence intervals (CI), with statistical comparisons performed with the Mann-Whitney test or Student's $t$ test. For categorical variables comparison was made using either the $\chi^{2}$ or Fisher exact tests. A $p$ value of less than 0.05 was considered statistically significant, whereas the confidence intervals were $95 \%$. All statistical calculations were performed using commercially available SAS statistical software version 9.4 (SAS Institute, Inc., Cary, NC, USA).

\section{Results}

The study population consisted of 494 consecutive patients (48.5\% male) at mean age of $73.4 \pm 11.5$ years. AF was classified as paroxysmal in $233(47.3 \%)$, as persistent in $109(22.1 \%)$, and as permanent in $151(30.6 \%)$ patients. As for the cardiovascular risk factors, hypertension was present in $387(78.5 \%)$ patients, diabetes mellitus in 164 $(33.3 \%)$ patients. Two hundred thirty-five patients $(47.7 \%)$ suffered from ischemic heart disease and 270 $(54.8 \%)$ were afflicted with heart failure. The population characteristics are shown in Table 1 . Mean $\mathrm{CHADS}_{2}$ score
Table 1 Baseline characteristics of the study population

\begin{tabular}{ll}
\hline Parameter & Value $(n=494)$ \\
\hline Age (years) & $73.4 \pm 11.5$ \\
Male & $239(48.5 \%)$ \\
Paroxysmal AF & $233(47.3 \%)$ \\
Persistent AF & $109(22.1 \%)$ \\
Permanent AF & $151(30.6 \%)$ \\
Hypertension & $387(78.5 \%)$ \\
Ischemic heart disease & $235(47.7 \%)$ \\
Asthma or COPD & $81(16.4 \%)$ \\
Heart failure & $270(54.8 \%)$ \\
Diabetes mellitus & $164(33.3 \%)$ \\
Prior stroke or TIA & $88(17.8 \%)$ \\
Weight (kg) & $78.2 \pm 19.3$ \\
Height (cm) & $166.3 \pm 10.1$ \\
BMI (kg/m $\left.{ }^{2}\right)$ & $28.8 \pm 6.5$ \\
Heart rate on admission (bpm) & $102.9 \pm 34.4$ \\
Heart rate on discharge (bpm) & $73.5 \pm 13.5$ \\
LVEF (\%) & $50.3 \pm 11.7$ \\
LVEDd (mm) & $50.3 \pm 7.2$ \\
IVDs (mm) & $12.8 \pm 2.1$ \\
LWPWd (mm) & $12.2 \pm 1.8$ \\
RVEDd (mm) & $31.0 \pm 5.2$ \\
LAd (mm) & $47.7 \pm 7.6$ \\
LA enlargement-total & $425(86.2 \%)$ \\
LA mildly enlarged & $99(20.0 \%)$ \\
LA moderately enlarged & $130(26.3 \%)$ \\
LA severely enlarged & $196(39.7 \%)$ \\
Mean CHADS & \\
Mean CHA ${ }_{2}$ DS ${ }_{2}$-VASc & $2.5 \pm 1.4$ \\
\hline Valus are mean & $4.3 \pm 1.8$ \\
\hline
\end{tabular}

Values are mean $\pm \mathrm{SD}$ or $n(\%)$

$A F$ atrial fibrillation, $B M I$ body mass index, bpm beats per minute, $C O P D$ chronic obstructive pulmonary disease, $S D$ standard deviation, TIA transient ischemic attack, $L V E D d$ left ventricular end-diastolic diameter, $L V E F$ left ventricular ejection fraction, IVSd interventricular septal end-systolic diameter, $L W P W d$ left ventricular posterior wall diastolic diameter, $L A d$ left atrial diameter, $R V E D d$ right ventricular diameter

was $2.5 \pm 1.4$ points while in $\mathrm{CHA}_{2} \mathrm{DS}_{2}$-VASc it was $4.3 \pm 1.8$.

Analysis of the echocardiographic parameters revealed that LA was enlarged in $426(86.2 \%)$ patients. Details of patients' characteristics according to presence of LA enlargement are presented in Table 2. The enlargement was classified as mild in $99(20.0 \%)$ patients. As moderate in $130(26.3 \%)$ patients, and as severe in $196(39.7 \%)$ patients.

Patients with enlarged LA more often had history of heart failure than patients with normal LA (59.1 vs. $27.9 \% ; p<0.0001)$, and had higher weight and body mass index $(79.3 \pm 19.6$ vs. $68.7 \pm 13.0 \mathrm{~kg} ; p=0.002$ and 
Table 2 Characteristics of the study population according to the presence of atrial enlargement

\begin{tabular}{|c|c|c|c|}
\hline Parameter & $\begin{array}{l}\text { Patients without LA } \\
\text { enlargement } \\
(n=68)\end{array}$ & $\begin{array}{l}\text { Patients with LA } \\
\text { enlargement } \\
(n=426)\end{array}$ & $p$ value \\
\hline Age (years) & $71.3 \pm 13.7$ & $73.7 \pm 11.0$ & 0.30 \\
\hline Male & $35(51.5 \%)$ & $204(48.0 \%)$ & 0.68 \\
\hline Paroxysmal AF & $52(76.5 \%)$ & $181(42.6 \%)$ & $<0.0001$ \\
\hline Persistent AF & $8(11.8 \%)$ & $101(23.8 \%)$ & 0.04 \\
\hline Permanent AF & $8(11.8 \%)$ & $143(33.6 \%)$ & 0.0005 \\
\hline Hypertension & $51(75.0 \%)$ & $336(79.1 \%)$ & 0.54 \\
\hline $\begin{array}{l}\text { Ischemic } \\
\text { heart disease }\end{array}$ & $29(42.6 \%)$ & $206(48.5 \%)$ & 0.44 \\
\hline $\begin{array}{l}\text { Asthma or } \\
\text { COPD }\end{array}$ & $11(16.2 \%)$ & $70(16.5 \%)$ & 0.90 \\
\hline Heart failure & $19(27.9 \%)$ & $251(59.1 \%)$ & $<0.0001$ \\
\hline $\begin{array}{l}\text { Diabetes } \\
\text { mellitus }\end{array}$ & $17(25.0 \%)$ & $147(34.6 \%)$ & 0.16 \\
\hline $\begin{array}{l}\text { Prior stroke or } \\
\text { TIA }\end{array}$ & $10(14.7 \%)$ & $78(18.4 \%)$ & 0.58 \\
\hline Height $(\mathrm{cm})$ & $164.9 \pm 8.2$ & $166.4 \pm 10.3$ & 0.48 \\
\hline Weight (kg) & $68.7 \pm 13.0$ & $79.3 \pm 19.6$ & 0.001 \\
\hline BMI $\left(\mathrm{kg} / \mathrm{m}^{2}\right)$ & $25.4 \pm 4.6$ & $29.2 \pm 6.5$ & 0.001 \\
\hline $\mathrm{TSH}(\mu \mathrm{IU} / \mathrm{ml})$ & $3.5 \pm 14.0$ & $2.1 \pm 5.3$ & 0.17 \\
\hline $\mathrm{K}^{+}(\mathrm{mmol} / \mathrm{L})$ & $4.3 \pm 0.7$ & $4.5 \pm 0.6$ & 0.10 \\
\hline $\begin{array}{l}\text { Heart rate on } \\
\text { admission } \\
\text { (bpm) }\end{array}$ & $102.3 \pm 33.4$ & $103.0 \pm 34.6$ & 0.94 \\
\hline $\begin{array}{l}\text { Heart rate on } \\
\text { discharge } \\
\text { (bpm) }\end{array}$ & $73.5 \pm 11.8$ & $73.5 \pm 13.7$ & 0.93 \\
\hline $\begin{array}{l}\text { Number of } \\
\text { risk factors }\end{array}$ & $2.4 \pm 1.5$ & $3.5 \pm 1.6$ & $<0.0001$ \\
\hline LVEF (\%) & $54.1 \pm 9.0$ & $49.7 \pm 12.0$ & 0.06 \\
\hline LVEDd (mm) & $47.0 \pm 5.3$ & $50.7 \pm 7.4$ & 0.01 \\
\hline IVDs (mm) & $12.4 \pm 2.0$ & $12.9 \pm 2.1$ & 0.26 \\
\hline PWd (mm) & $12.2 \pm 1.7$ & $12.2 \pm 1.8$ & 0.77 \\
\hline RVEDd (mm) & $28.8 \pm 4.5$ & $31.3 \pm 5.3$ & 0.01 \\
\hline LAd (mm) & $37.5 \pm 4.8$ & $49.1 \pm 6.7$ & $<0.0001$ \\
\hline $\begin{array}{l}\text { Mean } \\
\text { CHADS }_{2}\end{array}$ & $2.0 \pm 1.5$ & $2.6 \pm 1.3$ & 0.0005 \\
\hline $\begin{array}{l}\text { Mean } \\
\mathrm{CHA}_{2} \mathrm{DS}_{2^{-}} \\
\text {VASc }\end{array}$ & $3.8 \pm 2.0$ & $4.4 \pm 1.8$ & 0.02 \\
\hline
\end{tabular}

Bold values indicate statistical significance $(p<0.05)$

Values are mean \pm SD or $n(\%)$

$A F$ atrial fibrillation, $B M I$ body mass index, $b p m$ beats per minute, $C O P D$ chronic obstructive pulmonary disease, $S D$ standard deviation, TIA transient ischemic attack, LVEDd left ventricular end-diastolic diameter, $L V E F$ left ventricular ejection fraction, IVS $d$ interventricular septal end-systolic diameter, $L W P W d$ left ventricular posterior wall diastolic diameter, $L A d$ left atrial diameter, $R V E D d$ right ventricular diameter
A

$\mathrm{CHADS}_{2}$

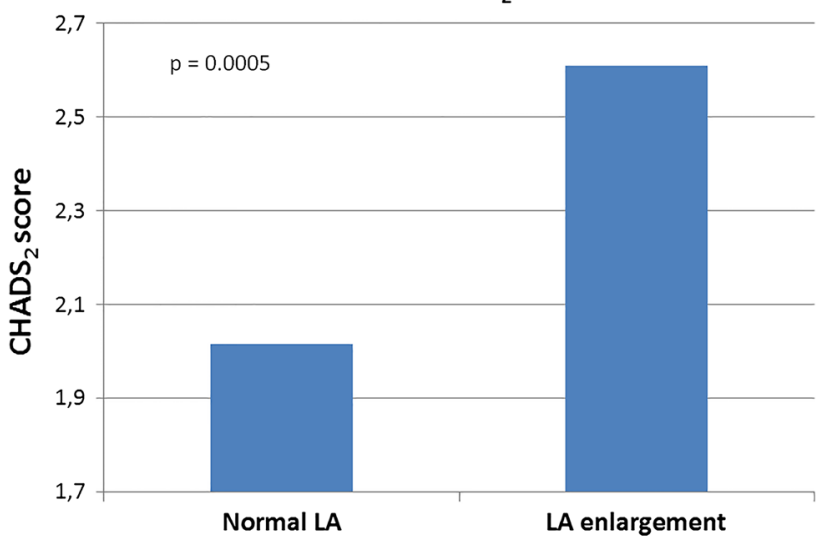

B

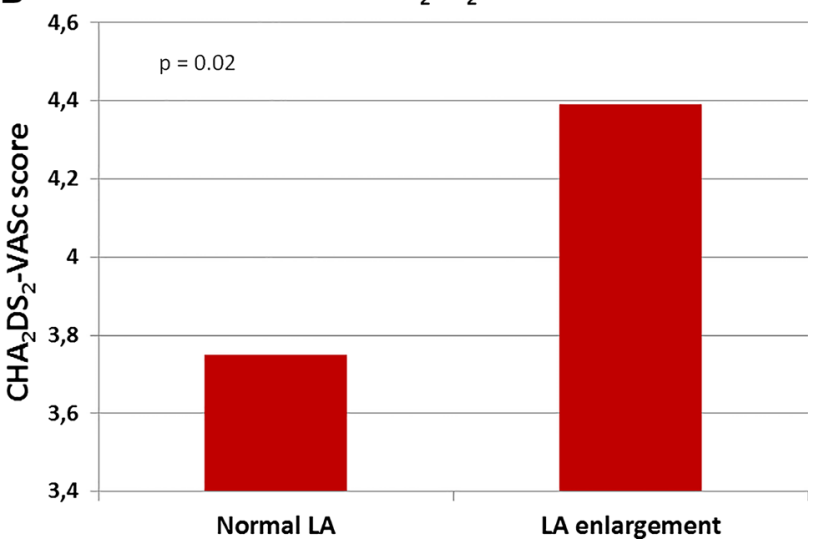

Fig. 1 Mean a CHADS 2 and $\mathbf{b} \mathrm{CHA}_{2} \mathrm{DS}_{2}$-VASc scores in patients with and without left atrial enlargement. Left atrial diameter criteria for enlargement normal LA: $+<39 \mathrm{~mm}, \hat{o}<41 \mathrm{~mm}$; mild LA enlargement: ㅇ 39-42 mm, ô 41-46 mm; moderate LA enlargement: ㅇ $43-46 \mathrm{~mm}$, ô $47-51 \mathrm{~mm}$; severe LA enlargement: $ᄋ \geq 47 \mathrm{~mm}$, $\hat{\sigma} \geq 52 \mathrm{~mm}$

$29.2 \pm 6.5$ vs. $25.4 \pm 4.6 \mathrm{~kg} / \mathrm{m}^{2} ; \quad p=0.001$, respectively). There were also differences regarding the type of arrhythmia. Paroxysmal AF was more often present (76.5 vs. $42.6 \% ; p<0.0001$ ) in the group with normal LA size, while persistent and permanent $\mathrm{AF}$ was more often in patients with LA enlargement then in those with normal LA size (23.8 vs. $11.8 \% ; p=0.04$ and 33.6 vs. $11.8 \%$; $p=0.0005$, respectively). Patients with enlarged LA compared to normal LA-sized population tend to present higher values of LVEDd $(50.7 \pm 7.4$ vs. $47.0 \pm 5.3 \mathrm{~mm}$; $p=0.01)$ and RVEDd ( $31.3 \pm 5.3$ vs. $28.8 \pm 4.5 \mathrm{~mm}$; $p=0.009)$. There was also a trend for lower LVEF in patients with enlarged LA $(49.7 \pm 12.0$ vs. $54.1 \pm 9.0 \%$; $p=0.06)$.

Thromboembolic risk assessed in $\mathrm{CHADS}_{2}$ and $\mathrm{CHA}_{2}$ $\mathrm{DS}_{2}$-VASc scores, was higher in patients with LA enlargement, than without it. Figure 1a shows that patients 
with LA enlargement had higher mean $\mathrm{CHADS}_{2}$ score $(2.0 \pm 1.5$ vs. $2.6 \pm 1.3 ; p=0.0005)$ than patients with normal LA, and the Fig. $1 \mathrm{~b}$ illustrates that also $\mathrm{CHA}_{2} \mathrm{DS}_{2^{-}}$ VASc showed similar tendency $(3.8 \pm 2.0$ vs. $4.4 \pm 1.8$; $p=0.02)$. After dividing patients into four categories: normal LAd, mildly, moderately, and severely enlarged LAd, we saw that along with the LA diameter also the risk in $\mathrm{CHADS}_{2}$ and $\mathrm{CHA}_{2} \mathrm{DS}_{2}$-VASc scores rose. For $\mathrm{CHADS}_{2}$ it was $2.0 \pm 1.5$ vs. $2.3 \pm 1.3$ vs. $2.6 \pm 1.3$ vs. $2.8 \pm 1.4$ ( $\mathrm{p}$ for trend $<0.001$ ), respectively (Fig. 2a) For $\mathrm{CHA}_{2} \mathrm{DS}_{2}$-VASc respective values were $(3.8 \pm 2.0$ vs. $4.0 \pm 1.7$ vs. $4.4 \pm 1.8$ vs. $4.6 \pm 1.8)(p$ for trend $=0.002)$ (Fig. 2b).

Similar trends were noticed, when LA enlargement was assessed basing on LAd index. Also in this case both mean CHADS2 $(p=0.004)$ and mean CHA2DS2-VASc $(p=0.02)$ values were the lowest in patients without LAd index-assessed LA enlargement, and the highest in patients

A
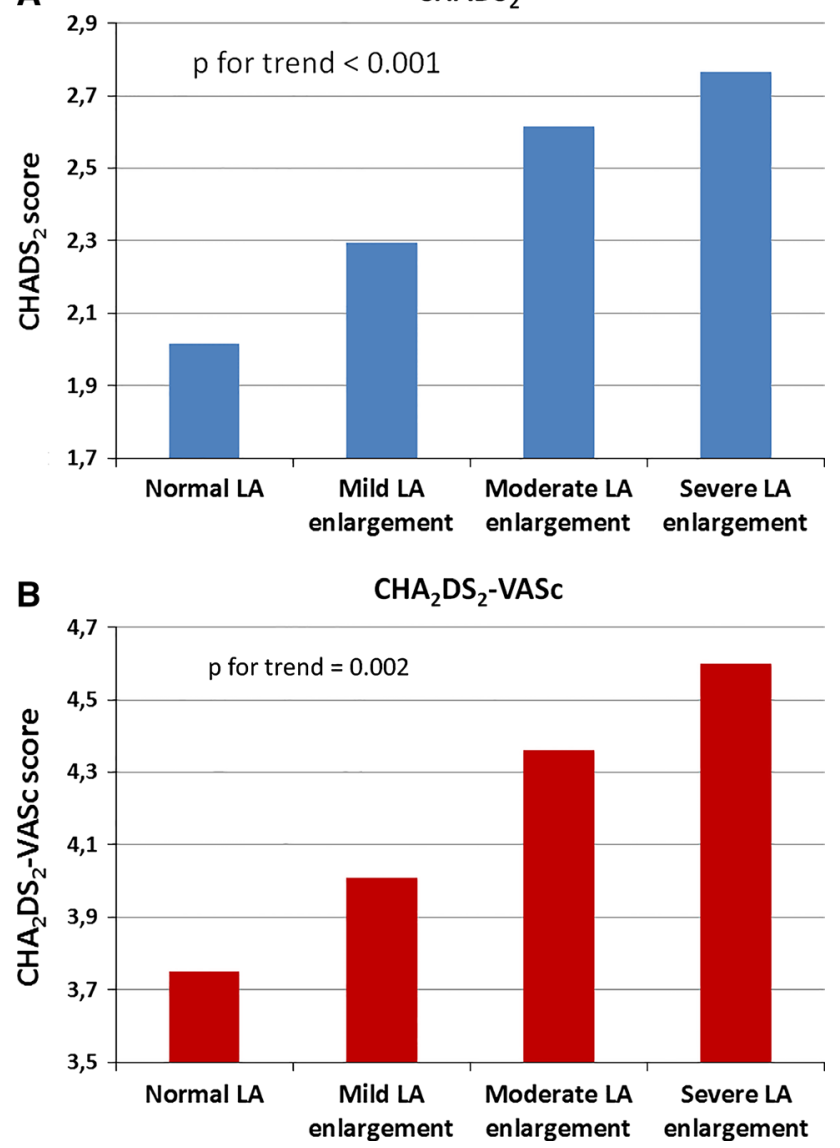

Fig. 2 Relationship between $\mathrm{CHADS}_{2}$ (a) and $\mathrm{CHA}_{2} \mathrm{DS}_{2}$-VASc (b) scores and severity of the left atrium enlargement. Left atrial diameter criteria for enlargement normal LA: $+<39 \mathrm{~mm}$, $\hat{\jmath}<41 \mathrm{~mm}$; mild LA enlargement: $+39-42 \mathrm{~mm}$, ô $41-46 \mathrm{~mm}$; moderate LA enlargement: $+43-46 \mathrm{~mm}$, ô $47-51 \mathrm{~mm}$; severe LA

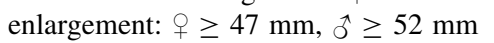

with severe enlargement. Results of this subanalysis are depicted in Fig. 3a, b.

\section{Discussion}

In the general population the prevalence of abnormal echocardiographic findings, including LA enlargement is high [13]. Echocardiographic abnormalities, especially associated with LA, are even more prevalent in AF patients [14]. Present study showed, that in a group of unselected AF patients, prevalence of LA enlargement is very high (up to $86 \%$ ). Interaction between the LA size and AF has been confirmed in many studies. Both conditions mutually exacerbate each other. In patients with diagnosed LA enlargement annual incidence of $\mathrm{AF}$ is higher than in patients with low LAd $[15,16]$. On the other hand, in patients with AF, LA size tends to increase with the time course of disease. The trend is not very marked in patients with paroxysmal AF, but especially visible in those with the persistent form of the arrhythmia [17]. LA size cannot be attributable only to AF, in many cases its diameter could be a marker for associated vascular disease (especially untreated hypertension) and other comorbidities [18]. Nevertheless, LA size influences strongly also the clinical course of the arrhythmia, especially when the rhythm control strategy is pursued i.e. by cardioversion or ablation. Outcomes of those strategies are worse in patients with enlarged LA [19].

In the context of the present study, the most important issue is the association between LA dimension and elevated stroke risk. It was previously established that the atrial enlargement, measured by various echocardiographic parameters, in the general population is predictive of cardiovascular events including stroke, coronary artery disease, congestive heart failure, and fatal cardiovascular disease [20]. Atrial enlargement promotes turbulent blood flow and therefore formation of the thrombi in the atrium. Enlarged LA diameter (with addition of elevated thromboembolic risk in the $\mathrm{CHADS}_{2}$ score) is a predictor of incident LA thrombi [21]. As a consequence, patients with LA enlargement are at higher risk of stroke, and majority of the stroke type occurring in this group are cardioembolic strokes [22, 23].

In the present study we showed, that LA enlargement correlates with higher risk of stroke in both $\mathrm{CHADS}_{2}$ and $\mathrm{CHA}_{2} \mathrm{DS}_{2}$-VASc scores, more over the higher the LAd, the higher were the mean point scores. $\mathrm{CHADS}_{2}$ and $\mathrm{CHA}_{2}$ $\mathrm{DS}_{2}$-VASc scores are widely used, simple risk assessment schemes, which showed to accurately predict the risk of stroke in AF patients [4, 24]. Other studies also showed them to be associated also with the risk of pulmonary embolism, or coronary artery disease severity [25, 26]. 


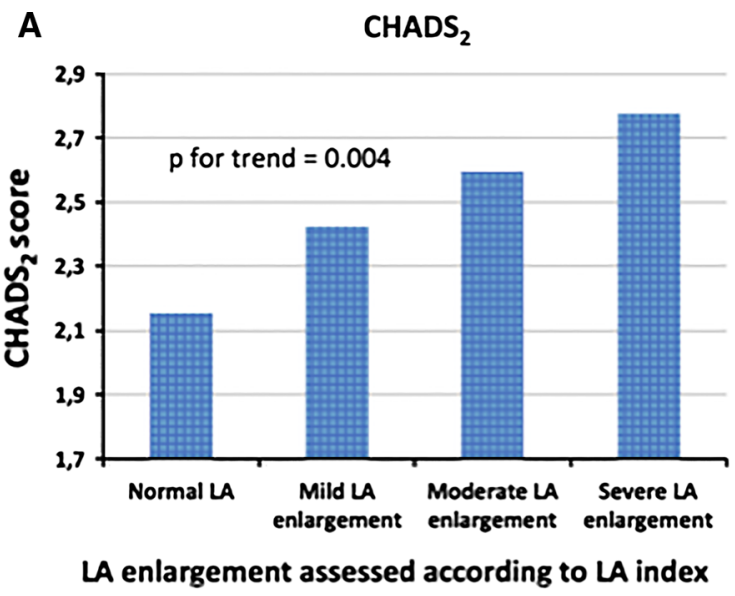

Fig. 3 Relationship between $\mathrm{CHADS}_{2}$ (a) and $\mathrm{CHA}_{2} \mathrm{DS}_{2}$-VASc (b) scores and severity of the left atrium enlargement assessed by LAd index for body surface area. Left atrial diameter index criteria

Nevertheless both schemes base only on medical history of patients, and do not incorporate any results from clinical tests. Therefore, they are prone to overlook some important issues, and underestimate thromboembolic risk, especially in patients in lower values range, which require anticoagulation therapy $[6,27]$. LAd is a parameter the easiest to obtain, and routinely assessed in majority of AF patients, which, as showed in the current study may help identify patients at high risk of stroke. In many cases it does not require any additional measurement or indexation. Nevertheless, additional analysis in which LAd was indexed for body surface area was performed, showing similar results. LAd index is a parameter more and standardized than LAd, but harder to obtain without additional measurements and calculators [11].

Previously $\mathrm{CHADS}_{2}$ and $\mathrm{CHA}_{2} \mathrm{DS}_{2}$-VASc were also proven to be associated with echocardiographic risk factors for thromboembolism including LA smoke, sludge, thrombus, and slow LA appendage emptying velocity [28, 29]. Nevertheless, in some cases assessed by the scores as "low risk" we can still find LA thrombi. It was shown that approximately $8 \%$ of patients with $\mathrm{CHADS}_{2}$ score of 0 or 1 have dense spontaneous echo contrast and $3 \%$ have LA thrombi [30]. This proves that assessment of LA structure is as important as risk predicted by $\mathrm{CHADS}_{2}$ and $\mathrm{CHA}_{2}$ $\mathrm{DS}_{2}$-VASc. Any additional tool, which will help properly assess the thromboembolic risk may be useful in the clinical practice, especially in the era, where many patients requiring anticoagulation do not receive such treatment $[31,32]$.

Current guidelines do not provide recommendations on the specific groups of patients in whom the TTE should be performed $[2,3]$. The guidelines say that TTE can provide useful information to guide clinical decision-making, but

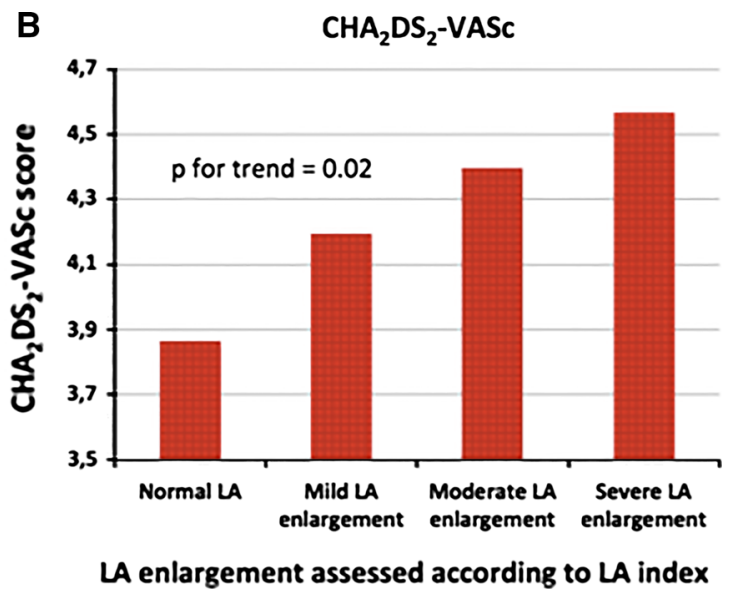

for enlargement normal LA: $15-23 \mathrm{~mm} / \mathrm{m}^{2}$; mild LA enlargement: 24-26 mm/ $/ \mathrm{m}^{2}$; moderate LA enlargement: $27-29 \mathrm{~mm} / \mathrm{m}^{2}$; severe LA enlargement: $\geq 30 \mathrm{~mm} / \mathrm{m}^{2}$

do not recommend performing it in all AF patients. It can be due to limited availability or insufficient cost-effectiveness of the routine screening. Nevertheless growing body of literature suggest that TTE, can be useful and should be performed in all patients with low $\mathrm{CHADS}_{2}$ or $\mathrm{CHA}_{2} \mathrm{DS}_{2}$-VASc scores, who do not fulfill score-based criteria for introduction of anticoagulation treatment. In these patients any potentially pro-thrombotic abnormality should be an indication for introduction of the anticoagulation treatment. This kind of approach was already proven to be cost-effective and provide additional quality-adjusted life-years (QALYs), in a model where TTE was routinely performed in patients with low $\mathrm{CHADS}_{2}$ to score, and anticoagulants were introduced in case of TTE-detected left atrial abnormality [33]. LAd measurement is one of the easiest to obtain even by non-cardiologist in a routine TTE, it can provide additional benefit in risk stratification and help guide stroke prevention in the borderline risk groups.

The most important limitation of the study is the lack of other echocardiographic parameters concerning LA (including its volume or function) being assessed. Previous studies showed that most of the LA parameters, including i.e. area in four-chamber view, volumes by the ellipsoid, single- and biplane area-length formulas are strongly associated with echocardiographic markers of stroke risk, including LA thrombus, and are almost equally predictive [34]. In the present study, it was decided to assess the most widely obtained echocardiographic parameter concerning LA, being LAd. It was decided to include in the study this particular parameter, because of its clinical utility and being easy to obtain, but LA diameter may not accurately reflect LA size, because atrial dilatation can be eccentric. Nevertheless, LAd is the main parameter used in the atrial enlargement definition. Other parameters are, in many 
cases, limited to the clinical studies, and therefore not very useful in everyday practice. Simple, routinely measured LAd gives the clinicians additional, important information in the decision making process on thromboembolic risk.

In conclusion, in a large group of unselected nonvalvular AF patients LA enlargement was highly prevalent. Presence of higher thromboembolic risk assessed by both $\mathrm{CHADS}_{2}$ and $\mathrm{CHA}_{2} \mathrm{DS}_{2}$-VASc scores was associated with LA enlargement. Echocardiographically assessed LA size may be an additional, easy to obtain parameter useful in thromboembolic risk stratification of AF patients.

Conflict of interest The authors have no conflicts of interest to disclose.

Open Access This article is distributed under the terms of the Creative Commons Attribution License which permits any use, distribution, and reproduction in any medium, provided the original author(s) and the source are credited.

\section{References}

1. Kirchhof P, Auricchio A, Bax J et al (2005) Outcome parameters for trials in atrial fibrillation: executive summary. Recommendations from a consensus conference organized by the German Atrial Fibrillation Competence NETwork (AFNET) and the European Heart Rhythm Association (EHRA). Eur Heart J 28:2803-2817

2. Camm AJ, Kirchhof P, Lip GY, European Heart Rhythm Association, European Association for Cardio-Thoracic Surgery et al (2010) Guidelines for the management of atrial fibrillation: the Task Force for the Management of Atrial Fibrillation of the European Society of Cardiology (ESC). Eur Heart J 31: 2369-2429

3. Camm AJ, Lip GY, De Caterina R, ESC Committee for Practice Guidelines (CPG) et al (2012) 2012 focused update of the ESC Guidelines for the management of atrial fibrillation: an update of the 2010 ESC Guidelines for the management of atrial fibrillation. Developed with the special contribution of the European Heart Rhythm Association. Eur Heart J 33:2719-2747

4. Gage BF, Waterman AD, Shannon W et al (2001) Validation of clinical classification schemes for predicting stroke: results from the National Registry of Atrial Fibrillation. JAMA 285: 2864-2870

5. Lip GY, Nieuwlaat R, Pisters R et al (2010) Refining clinical risk stratification for predicting stroke and thromboembolism in atrial fibrillation using a novel risk factor-based approach: the Euro Heart Survey on atrial fibrillation. Chest 137:263-272

6. Szymanski FM, Filipiak KJ, Platek AE et al (2014) Assessment of CHADS2 and CHA 2DS 2-VASc scores in obstructive sleep apnea patients with atrial fibrillation. Sleep Breath. doi:10.1007/ s11325-014-1042-5

7. The Stroke Prevention in Atrial Fibrillation Investigators (1992) Predictors of thromboembolism in atrial fibrillation: II. Echocardiographic features of patients at risk. The Stroke Prevention in Atrial Fibrillation Investigators. Ann Intern Med 116:6-12

8. Lee JM, Shim J, Uhm JS et al (2014) Impact of increased orifice size and decreased flow velocity of left atrial appendage on stroke in nonvalvular atrial fibrillation. Am J Cardiol 113:963-969
9. Kiliszek M, Miązek N, Peller M et al (2014) Influence of left atrial size on outcome of pulmonary vein isolation in patients with atrial fibrillation. Kardiol Pol 72:1135-1140

10. Lemola K, Sneider M, Desjardins B et al (2004) Effects of left atrial ablation of atrial fibrillation on size of the left atrium and pulmonary veins. Heart Rhythm 1:576-581

11. Lang RM, Bierig M, Devereux RB, American Society of Echocardiography's Nomenclature and Standards Committee, Task Force on Chamber Quantification, American College of Cardiology Echocardiography Committee, American Heart Association, European Association of Echocardiography, European Society of Cardiology et al (2006) Recommendations for chamber quantification. Eur J Echocardiogr 7:79-108

12. Rudski LG, Lai WW, Afilalo J et al (2010) Guidelines for the echocardiographic assessment of the right heart in adults: a report from the American Society of Echocardiography endorsed by the European Association of Echocardiography, a registered branch of the European Society of Cardiology, and the Canadian Society of Echocardiography. J Am Soc Echocardiogr 23:685-713

13. Kopeć G, Sobień B, Podolec M et al (2014) The prevalence of abnormal echocardiographic findings in a sample of urban adult population. Kardiol Pol 72:42-49

14. Lazoura O, Reddy T, Shriharan M et al (2012) Prevalence of left atrial anatomical abnormalities in patients with recurrent atrial fibrillation compared with patients in sinus rhythm using multislice CT. J Cardiovasc Comput Tomogr 6:268-273

15. Andersen JS, Egeblad H, Abildgaard U et al (1991) Atrial fibrillation and left atrial enlargement: cause or effect? J Intern Med 229:253-256

16. Parkash R, Green MS, Kerr CR, Canadian Registry of Atrial Fibrillation et al (2004) The association of left atrial size and occurrence of atrial fibrillation: a prospective cohort study from the Canadian Registry of Atrial Fibrillation. Am Heart J 148:649-654

17. Casaclang-Verzosa G, Gersh BJ, Tsang TS (2008) Structural and functional remodeling of the left atrium: clinical and therapeutic implications for atrial fibrillation. J Am Coll Cardiol 51:1-11

18. Dittrich HC, Pearce LA, Asinger RW et al (1999) Left atrial diameter in nonvalvular atrial fibrillation: an echocardiographic study. Stroke Prevention in Atrial Fibrillation Investigators. Am Heart J 137:494-499

19. Zhuang J, Wang Y, Tang K et al (2012) Association between left atrial size and atrial fibrillation recurrence after single circumferential pulmonary vein isolation: a systematic review and metaanalysis of observational studies. Europace 14:638-645

20. Kizer JR, Bella JN, Palmieri V et al (2006) Left atrial diameter as an independent predictor of first clinical cardiovascular events in middle-aged and elderly adults: the Strong Heart Study (SHS). Am Heart J 151:412-418

21. Scherr D, Dalal D, Chilukuri K et al (2009) Incidence and predictors of left atrial thrombus prior to catheter ablation of atrial fibrillation. J Cardiovasc Electrophysiol 20:379-384

22. Olshansky B, Heller EN, Mitchell LB et al (2005) Are transthoracic echocardiographic parameters associated with atrial fibrillation recurrence or stroke? Results from the Atrial Fibrillation Follow-Up Investigation of Rhythm Management (AFFIRM) study. J Am Coll Cardiol 45:2026-2033

23. Shin HY, Jeong IH, Kang CK et al (2013) Relation between left atrial enlargement and stroke subtypes in acute ischemic stroke patients. J Cerebrovasc Endovasc Neurosurg 15:131-136

24. Lip GY, Frison L, Halperin JL et al (2010) Identifying patients at high risk for stroke despite anticoagulation: a comparison of contemporary stroke risk stratification schemes in an anticoagulated atrial fibrillation cohort. Stroke 41:2731-2738

25. Saliba W, Rennert G (2014) $\mathrm{CHA}_{2} \mathrm{DS}_{2}$-VASc score is directly associated with the risk of pulmonary embolism in patients with atrial fibrillation. Am J Med 127:45-52 
26. Cetin M, Cakici M, Zencir C et al (2013) Prediction of coronary artery disease severity using $\mathrm{CHADS}_{2}$ and $\mathrm{CHA}_{2} \mathrm{DS}_{2}$-VASc scores and a newly defined $\mathrm{CHA}_{2} \mathrm{DS}_{2}$-VASc-HS score. Am J Cardiol 113:950-956

27. Welles CC, Whooley MA, Na B et al (2011) The CHADS2 score predicts ischemic stroke in the absence of atrial fibrillation among subjects with coronary heart disease: data from the Heart and Soul Study. Am Heart J 162:555-561

28. Willens HJ, Gómez-Marín O, Nelson K et al (2013) Correlation of CHADS2 and CHA2DS2-VASc scores with transesophageal echocardiography risk factors for thromboembolism in a multiethnic United States population with nonvalvular atrial fibrillation. J Am Soc Echocardiogr 26:175-184

29. Puwanant S, Varr BC, Shrestha K et al (2009) Role of the $\mathrm{CHADS}_{2}$ score in the evaluation of thromboembolic risk in patients with atrial fibrillation undergoing transesophageal echocardiography before pulmonary vein isolation. J Am Coll Cardiol 54:2032-2039

30. Kleemann T, Becker T, Strauss M et al (2009) Prevalence and clinical impact of left atrial thrombus and dense spontaneous echo contrast in patients with atrial fibrillation and low $\mathrm{CHADS}_{2}$ score. Eur J Echocardiogr 10:383-388

31. Lip GY, Laroche C, Dan GA et al (2014) A prospective survey in European Society of Cardiology member countries of atrial fibrillation management: baseline results of EURObservational Research Programme Atrial Fibrillation (EORP-AF) Pilot General Registry. Europace 16:308-319

32. Derezinski T, Wasikowska B, Strzebonski B et al (2013) Outpatient oral anticoagulation in Poland in 2012: a single centre experience. Kardiol Pol 71:1135-1139

33. Simpson E, Stevenson M, Scope A, Poku E, Minton J, Evans P (2013) Echocardiography in newly diagnosed atrial fibrillation patients: a systematic review and economic evaluation. Health Technol Assess 17:1-263

34. Faustino A, Providência R, Barra S et al (2014) Which method of left atrium size quantification is the most accurate to recognize thromboembolic risk in patients with non-valvular atrial fibrillation? Cardiovasc Ultrasound 12:28 